\title{
The properties of slag-silica fume ternary blended mortar with quarry dust
}

\author{
Chow Wee Kang ${ }^{1,}{ }^{*}$, Cheah Chee Ban ${ }^{1}$, Oo Chuan Wei², Part Wei Ken ${ }^{3}$ and Leow Khang Heng ${ }^{3}$ \\ 1 School of Housing, Building \& Planning, Universiti Sains Malaysia, 11800 Gelugor, Penang, Malaysia, Phone: +60177824893 \\ ${ }^{2}$ School of Chemical Sciences, Universiti Sains Malaysia, 11800 Gelugor, Penang, Malaysia \\ ${ }^{3}$ Macro Dimension Concrete Sdn. Bhd. Bandar Amanjaya, Sungai Petani, Kedah 08000 Malaysia.
}

\begin{abstract}
High carbon emissions of manufactured Portland cement in the concrete industry have incurred several interests in reducing the use of Portland cement by partially replacing it with supplementary cementitious materials. Most of which, are by-products from other manufacturing industries. Hence, the main purpose of this study is to investigate the effects of different combinations of ternary blended mortars incorporating supplementary cementitious materials such as Ground Granulated Blast Furnace Slag (GGBS) and Densified Silica Fume (DSF). In this study, mortars were prepared with $100 \%$ quarry dust and GGBS was replaced with DSF at $2 \%$ step increments up to $16 \%$ at a w/b ratio of 0.24 . At the same time OPC content was fixed at $50 \%$. The compressive and flexural strength, drying shrinkage, and porosity of mortars were all tested. The results indicated that the increasing DSF content increases; GGBS reduces the superplasticizer dosage for the desired workability of the mortar. The utilization GGBS and DSF has improved the performances ternary blended mortar incorporating quarry dust as a fine aggregate in terms of mechanical strength, drying shrinkage and total porosity tested. The high strength ternary blended mortar incorporating GGBS and DSF exhibited optimum mechanical and durability performance at the OPC:GGBS:DSF ratio of 50:38:12.
\end{abstract}

ARTICLE HISTORY

Revised: $30^{\text {th }}$ Sept 2019

Accepted: $16^{\text {th }}$ Oct 2019

\section{KEYWORDS}

High strength mortar; ternary blended;

GGBS;

DSF;

quarry dust.

\section{INTRODUCTION}

The construction industry is one of the industry sectors that contribute to the economic growth of a country. So, the global cement demand for the fabrication of buildings and infrastructures have been growing significantly over previous years. Cement is widely used as primary binder for the production of mortar, concrete, blockwork and bricks. This is due to low cost and widespread availability of limestone, shales and other materials that utilize ordinary Portland cement production. However, it incurs intensive energy and resources in order to produce ordinary Portland cement from native limestone into reactive cementitious powder. This is because its production process brings inevitably hazardous discharge to the environment that lead to climate change and global warming due to the high amount of $\mathrm{CO}_{2}$ emissions. It has been recorded that the cement manufacturing sector contributes to $7 \%$ of the global anthropogenic carbon dioxide emissions [1]. It has been estimated that the global cement production has reached 4.10 million tonnes in 2015 [2]. By 2020, the amount of ordinary Portland cement production is predicted to increase by approximately $115 \%$ to $180 \%$ compared to the 1990s, and expected to increase four times higher by 2050 due to the drastic increase of world cement demands [3]. During the cement manufacturing process, calcium carbonate is heated to produce lime and carbon dioxide gas that is released into the atmosphere. It is reported that nearly $900 \mathrm{~kg}$ of $\mathrm{CO}_{2}$ gas will be produced for every 1 ton of cement produced [4]. Hence, great efforts on developing concrete compositions with lower possible environmental impacts that reduce of use of ordinary Portland cement in the concrete industry must be taken. The over-reliance on the use of ordinary Portland cement as a primary binder of cement products must also be addressed.

An efficient approach in the reduction of the use of ordinary Portland cement in the construction industry on cement products is partially replacing the cementitious content with supplementary cementitious materials such as; pozzolanic and fine filler materials. This is done to an extent of an optimum usage level to obtain the desired performance and quality in terms of mechanical and durability performance of concrete products produced. In this study, high strength mortar was produced by partial substitution of OPC with Ground Granulated Blast Furnace Slag (GGBS) and Densified Silica Fume (DSF). GGBS is a by-product of the iron manufacturing industry that has been specially treated by rapid cooling or quenching below $800^{\circ} \mathrm{C}$. This is in order to obtain a good chemical reactivity with a high content of silicates and aluminosilicates of calcium and of other bases. The $\mathrm{Ca}(\mathrm{OH})_{2}$ reacts with GGBS in the presence of water to form calcium-silicate hydrate and calcium-aluminate hydrate, widely known as secondary hydration that refines pore structure and contributes to the long term strength development [5]. Meanwhile, the $\mathrm{CO}_{2}$ emissions are recorded to be decreased by approximately 0.5 tons when the replacement levels up to $50 \%$ of ordinary Portland cement are achieved. It was revealed $\mathrm{CO}_{2}$ emissions related to its manufacture and placement of concrete concluded that replacing GGBS up to $40 \%$, equivalent strength could be obtained compared to $100 \%$ OPC concrete while carbon emissions declined $22 \%$ [6].

With the use of GGBS as a partial replacement material to OPC, many researchers have concluded that the mechanical and durability properties of mortar or concrete products have been improved. Researchers have also agreed that the 
optimum usage of 50-60\% GGBS achieved higher mechanical strength than neat OPC mortar or concrete [7-9]. The performance showed a decline when the replacement level increased up to 80\% [10]. The mechanical strength of mortar or concrete also showed improvement with the fineness of GGBS due to the increased effectiveness pore refinement by formation of secondary C-S-H bonds in the pore structure [11]. Moreover, the utilization of GGBS enhanced the workability of fresh mortar or concrete by better particle dispersion however may lead to bleeding and segregation above $60 \%$ of its substitution level [9].

Silica Fume (SF) is a by-product from the smelting process of the silicon and ferrosilicon industry. This is a form of natural pozzolan that is widely used in concrete production which improves the durability properties of concrete products through pozzolanic reactions using free lime, pore refinement and paste-aggregate interfacial improvements. The mechanical properties of concrete products containing silica fume are improved due to the micro-filling function of very fine spherical particles. These silica fume particles have enabled a high pozzolanic reaction to consume huge amounts of $\mathrm{Ca}(\mathrm{OH})_{2}$. This in turn improves the pore structure of the matrix which contributes to the higher mechanical strength development of mortar or concrete. This is done by accelerating the rate of $\mathrm{C}_{3} \mathrm{~S}$ and $\mathrm{C}_{3} \mathrm{~A}$ hydration to increase the formation of calcium silicate hydrates $(\mathrm{C}-\mathrm{S}-\mathrm{H})$ at an early age. The gaps between cement grains and cement hydration products are then filled due to its smaller particle size than the cement particles. Silica fume improves the early strength development of mortar or concrete. The acceleration on the strength development is facilitated by the fine silica fume particles which provide a nucleating site to hydration products of cement such as; ettringite, lime and C-S-H bonds that densify the pore structure of the matrix.

There were authors concluded that the optimum usage of silica fume that obtained highest compressive strength and flexural strength was from $10-15 \%$ of the total weight of binder $[1,4,12]$. There were also studies which have shown that the mechanical strength of mortar is greatest at 15-22\% of SF [13]. However, the mechanical strength declined when the SF content increased up to $30 \%$. The workability of concrete decreased when incorporated with a higher volume of SF [5]. A higher dosage of superplasticizer or water demand was needed to maintain the same workability achieved by neat OPC concrete [14-15]. The utilization of SF showed improved stability of the fresh mixture by a reduction of bleeding. For durability properties, the porosity of mortar was reduced due to the densification of the microstructure of the matrix and reduced pore size and pore volume [16-17]. Meanwhile, the drying shrinkage of the steel furnace slag-silica fume concrete was similar to plain OPC concrete at an early age. The drying shrinkage was much lower at a late age as the steel furnace slag-silica fume concrete became denser and less porous than the plain OPC concrete [3, 18].

With references to several studies done by researchers as prescribed earlier, the mechanical properties of binary mortar with single supplementary cementitious materials as OPC replacement material at a normal water-to-binder ratio and river sand as fine aggregates are commonly used. Thus, there is limited knowledge on the mechanical performance and workability of mortar. This includes utilizing GGBS and DSF in a ternary blended system with quarry dust as fine aggregates at a very low constant water-to-binder ratio. This study is dedicated to investigate various mechanical properties and workability of ternary blended high strength mortar. GGBS was incorporated with DSF as well as quarry dust as fine aggregate to obtain the optimum binder composition exhibited for the most favourable mechanical strength performance.

\section{METHODS AND MATERIALS}

\section{Portland Cement}

Ordinary Portland cement (CEM 42.5N), commercially available in local markets with a specific gravity of 3.15 was used in these studies. There was 50\% ordinary Portland cement used as one of the main binders of this ternary blended mortar fabrication. The chemical composition of ordinary Portland cement used is shown in Table 1.

\section{Ground Granulated Blast Furnace Slag}

Ground Granulated Blast Furnace Slag (GGBS) used in this study was obtained from local sources. It has an average fineness of $4620 \mathrm{~cm}^{2} / \mathrm{g}$ and a specific gravity of 2.93. The main chemical composition of GGBS used is as shown in Table 1. The SEM image of GGBS used is shown in Figure 1. 


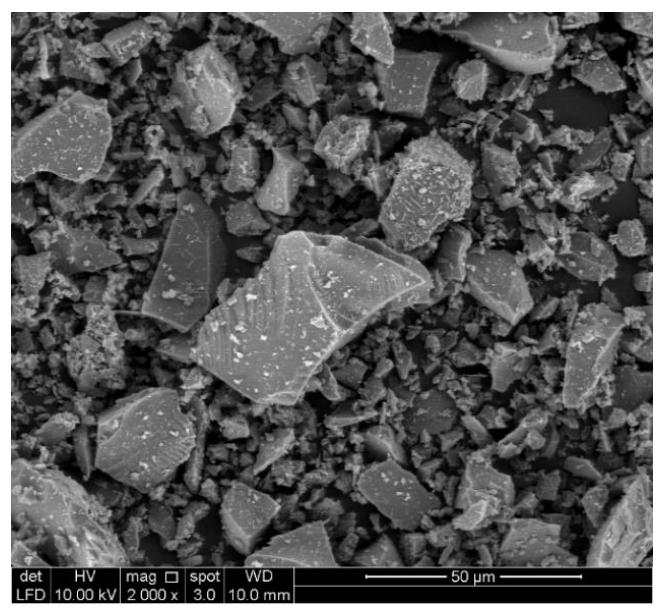

Figure 1. SEM image of GGBS.

\section{Densified Silica Fume}

Densified Silica Fume (DSF) is a form of micro silica fume densified into a higher bulk density up to a maximum of approximately 400 to $720 \mathrm{~kg} / \mathrm{m}$ for ease of transportation. In this study, the DSF with a specific gravity of 2.28 was used. The main constituent of DSF was as shown in Table 1. The SEM image of DSF is shown in Figure 2. It was noticed that the micro silica particles were clustered into large near spherical 'pellets' with mean diameters of about $100 \mu \mathrm{m}$ which is the effect of the silica fume densification process.
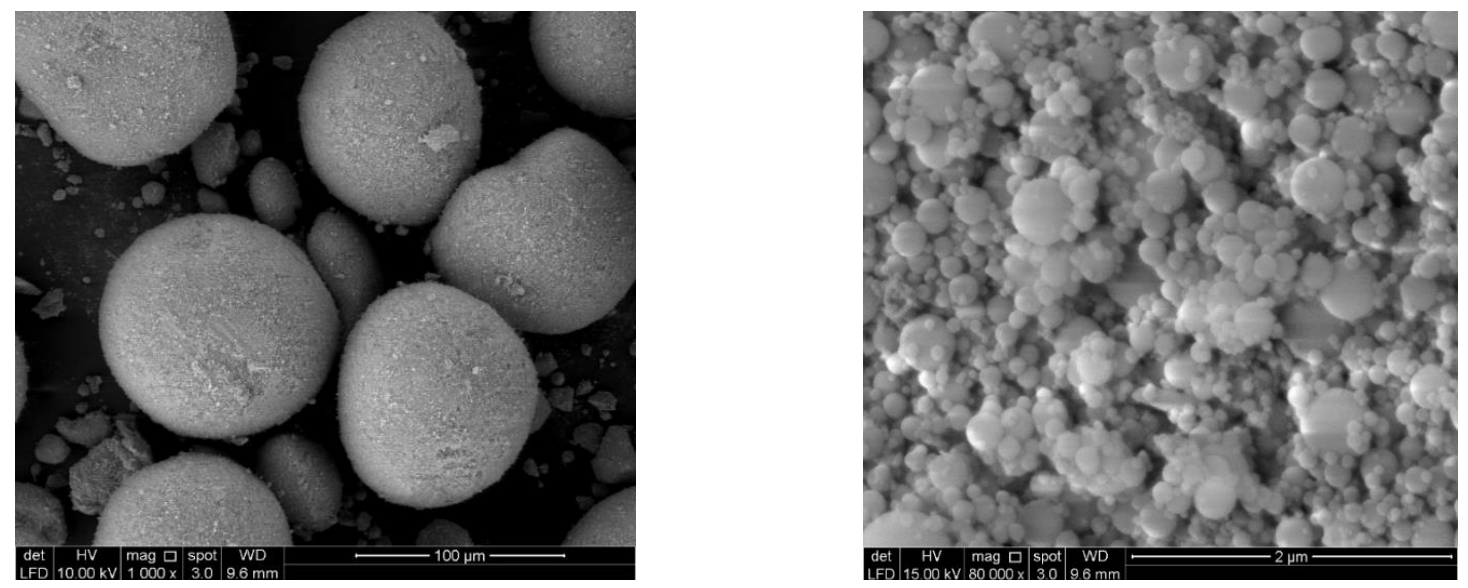

Figure 2. SEM image of DSF at 1000x and 80000x magnification.

Table 1. Chemical composition of binder.

\begin{tabular}{cccc}
\hline \multirow{2}{*}{ Chemical compound } & \multicolumn{3}{c}{ \% of total mass } \\
\cline { 2 - 4 } & OPC & GGBS & DSF \\
\hline $\mathrm{MgO}_{2} \mathrm{~A}_{3}$ & 1.50 & 6.08 & 4.60 \\
$\mathrm{SiO}_{2}$ & 3.60 & 13.27 & 0.27 \\
$\mathrm{P}_{2} \mathrm{O}_{5}$ & 22.40 & 32.84 & 84.00 \\
$\mathrm{SO}_{3}$ & 0.06 & 0.01 & 0.05 \\
$\mathrm{Cl}$ & 3.10 & & 0.44 \\
$\mathrm{~K}_{2} \mathrm{O}$ & & 0.36 & 2.40 \\
$\mathrm{CaO}$ & 0.34 & 40.80 & 2.70 \\
$\mathrm{TiO}_{2}$ & 65.60 & 0.47 & 0.66 \\
$\mathrm{MnO}_{\mathrm{Fe}}$ & 0.17 & 0.14 & 0.09 \\
$\mathrm{ZnO}$ & 0.03 & 0.28 & 0.54 \\
$\mathrm{SrO}$ & 2.90 & & 0.10 \\
$\mathrm{PbO}$ & trace & & 0.01 \\
$\mathrm{CuO}_{\mathrm{Rb}}$ & 0.04 & & trace \\
$\mathrm{Na}_{2} \mathrm{O}$ & 0.01 & & 0.02 \\
& & & 4.20 \\
\hline
\end{tabular}




\section{Fine Aggregate}

The fine aggregate used in mortar in this study was graphite quarry dust obtained from a local graphite quarry. The quarry dust is a by-product of the crushing process of granite rock for aggregate use in concrete. In this study, the quarry dust with the specific gravity of 2.65 and fineness modulus of 3.00 were used. The quarry dust was washed to remove organic impurities and fraction retention between $75 \mu \mathrm{m}$ and $5 \mathrm{~mm}$ collected by air drying for mortar fabrication use.

\section{Chemical Admixture}

The chemical admixture used in this study was polycarboxylate ether (PCE) based at a high range water reducing superplasticizer supplied by BASF with the commercial designation of SKY 8808. The dosage of each mortar design was obtained by gradually adjusting the desired flow of mortar at a fixed water-to-binder ratio.

\section{Mixture Proportioning and Mixing}

In this study, the binder to fine aggregates ratio of designed mortar was prepared with a fixed ratio of 1:2.75 as stated in ASTM C 109/C 109M-16a, 2016 [19]. The quarry dust was fully used as the fine aggregates of the mortar prepared. A total of 50\% OPC was replaced by GGBS and DSF. DSF was used as a substitution of GGBS from 0\% to $16 \%$ with increments of $2 \%$ by total binder weight. Thus, there were 10 different mortar mix proportions prepared in the study, including one control OPC mix as a reference mix at the constant water-to-binder ratio of 0.24 . The dosage of the high range water reducing chemical admixture used for each mortar mix proportion was adjusted to achieve a slump class of S4. The mix proportion of mortars, dosages of chemical admixture needed and flow of mortar obtained were recorded in Table 2.

Table 2. Mix proportion of mortars.

\begin{tabular}{ccccccccc}
\hline $\begin{array}{c}\text { Mix } \\
\text { code }\end{array}$ & $\begin{array}{c}\text { OPC } \\
\left(\mathrm{kg} / \mathrm{m}^{3}\right)\end{array}$ & $\begin{array}{c}\mathrm{GGBS} \\
\left(\mathrm{kg} / \mathrm{m}^{3}\right)\end{array}$ & $\begin{array}{c}\text { DSF } \\
\left(\mathrm{kg} / \mathrm{m}^{3}\right)\end{array}$ & $\begin{array}{c}\text { Water } \\
\left(\mathrm{kg} / \mathrm{m}^{3}\right)\end{array}$ & $\begin{array}{c}\text { Quarry } \\
\text { dust } \\
\left(\mathrm{kg} / \mathrm{m}^{3}\right)\end{array}$ & $\begin{array}{c}\text { w/b } \\
\text { ratio }\end{array}$ & $\begin{array}{c}\text { Chemical } \\
\text { admixture dosage } \\
(\% \text { by total mass of } \\
\text { binder })\end{array}$ & $\begin{array}{c}\text { Flow } \\
(\mathrm{mm})\end{array}$ \\
\hline Control & 626.88 & 0 & 0 & 150.45 & 1723.93 & 0.24 & 4.50 & 160 \\
S0 & 311.12 & 311.12 & 0 & 149.34 & 1711.14 & 0.24 & 3.80 & 180 \\
S2 & 310.83 & 298.39 & 12.43 & 149.20 & 1709.54 & 0.24 & 4.50 & 200 \\
S4 & 310.53 & 285.69 & 24.84 & 149.06 & 1707.94 & 0.24 & 4.80 & 185 \\
S6 & 310.24 & 273.01 & 37.23 & 148.92 & 1706.34 & 0.24 & 5.00 & 175 \\
S8 & 309.95 & 260.36 & 49.59 & 148.78 & 1704.75 & 0.24 & 5.60 & 220 \\
S10 & 309.66 & 247.73 & 61.93 & 148.64 & 1703.15 & 0.24 & 5.80 & 185 \\
S12 & 309.38 & 235.13 & 74.25 & 148.50 & 1701.57 & 0.24 & 6.00 & 200 \\
S14 & 309.09 & 222.54 & 86.54 & 148.36 & 1699.98 & 0.24 & 6.20 & 220 \\
S16 & 308.80 & 209.98 & 98.82 & 148.22 & 1698.40 & 0.24 & 6.20 & 230 \\
\hline
\end{tabular}

\section{Mixing, Forming and Curing}

Every batch of mortar was mixed homogeneously by using an epicyclic mechanical mixer with the specifications prescribed in ASTM C305-14, 2014 [20]. The slump of the mortar was tested using a flow table with the specifications complying with the steps of the standard prescribed in ASTM C230/C230M-14, 2014 [21]. The flow of the mixture was then slowly adjusted by an extra dosage of a chemical admixture until the desired workability of the mortar was achieved. Finally, the fresh mortar was placed into moulds prepared for the assessment of different testing parameters for the experimental programme. The mortar specimens were allowed to set in the moulds prepared for 24 hours before removal for water curing in a water curing tank following the prescription stated in ASTM C192/C 192M-18, 2018 [22].

\section{Flexural Strength and Compressive Strength}

The flexural strength of mortar prisms prepared was determined by the methods and procedures as prescribed in ASTM C348-18, 2018 [23]. The prisms were removed from the curing tank for flexural strength assessment at the prescribed testing ages. The compressive strength of every batch of the mortar designs were tested in accordance to the procedures stated in ASTM C349-18, 2018 using portions of the broken prisms from flexural strength test. The mortar specimens were tested on 7, 28, 56 and 90 days [24].

\section{Drying Shrinkage}

The prisms for the dry shrinkage assessments of the mortars were prepared with the dimensions $75 \times 75 \times 285 \mathrm{~mm}$ and were air cured in an atmospheric condition with humidity level of $50 \pm 5 \%$. The temperature was maintained at $23 \pm 2^{\circ} \mathrm{C}$ at various durations up to 112 days. The methods and procedures of the drying shrinkage assessment were conducted as prescribed in ASTM C596-18, 2018 using a length comparator [25]. 


\section{Porosity}

Cylindrical samples with the dimension $50 \mathrm{~mm} \varnothing \times 100 \mathrm{~mm}$ were prepared for each mortar mix design at each testing age then prepared for their porosity assessment. Before the assessment, the samples were dried in an oven for $72 \pm 2$ hours. The samples were allowed to cool down for $24 \pm 0.5$ hours and their dry weight was recorded. The samples were then placed into a desiccator filled with water and sealed tightly with grease. The porosity of the mortar samples was allowed to be vacuumed in the desiccator with a vacuum pump. The pump was connected to an exhaust and placed inside the desiccator for $72 \pm 2$ hours until no effervescence was observed. The samples were then taken out, weighted by an electronic balance in air and suspended in water. Hence, the porosity of the sample was calculated by the following formula as Equation. (1).

$$
\text { Porosity }=\left[\left(\mathrm{m}_{\text {sat }}-\mathrm{m}_{\text {dried }}\right) /\left(\mathrm{m}_{\text {sat }}-\mathrm{m}_{\mathrm{water}}\right)\right] \times 100
$$

where, $\mathrm{m}_{\text {sat }}$ is mass saturated specimen, $\mathrm{m}_{\text {dried }}$ is dried mass of specimen and $\mathrm{M}_{\mathrm{water}}$ is mass of saturated specimen in water.

\section{RESULTS AND DISCUSSION}

\section{Flexural Strength}

In Figure 3, the results of the flexural strength for all mortar designs were recorded for all 4 testing ages selected. Based on the results obtained, the control mortar mix showed a higher flexural strength at the early age of 7 days compared to the other mortars with GGBS and DSF. This was due to the fact that the other mortar designs had 50\% of OPC replaced with GGBS and DSF which led to a slower hydration rate and strength development than the control mix with $100 \%$ OPC. It was recorded that the control mix achieved $14.13 \mathrm{MPa}$ at 7 days while other mortars exhibited $3.4-16 \%$ less flexural strength compared to the control mortar. For the prolonged curing duration of 28 days, the flexural strength of the control OPC mix was the lowest while the flexural strength of S12 was the highest with a value of $17.27 \mathrm{MPa}$ or $15.86 \%$ higher than the control mix. These results were attributed to the hydration of GGBS and DSF that consumes the $\mathrm{Ca}(\mathrm{OH})_{2}$ produced from the hydration of Portland cement forming small sized secondary C-A-S-H and C-S-H gels, which in turn, filled the pores in the microstructure. In general, the flexural strength of the mortar increased with curing. A corresponding increase in flexural strength was also observed when the DSF content was elevated from $2 \%$ up to $12 \%$ in replacement of GGBS. The flexural strength started to decline from the optimum level when the DSF content was increased further to $14-16 \%$. The flexural strength of S12 at 90 days was $18.23 \mathrm{MPa}$ which was $12.25 \%$ higher than control mix. At the optimum binder composition level, the $\mathrm{Ca}(\mathrm{OH})_{2}$ produced from the hydration of ordinary Portland cement was adequate for the secondary hydration of GGBS and DSF glassy alumina and silica phase to form secondary C-S-H and C-A-S-H. These were shown to contribute to the later age flexural strength development. Further increments of DSF caused insufficient $\mathrm{CaO}$ content resulting in a reaction with the silica fume. Calcium aluminosilicate gel was then produced leading to a surplus of unreacted DSF in the ternary blended cement system which acts as a filler between hydrate phases and aggregates [26].

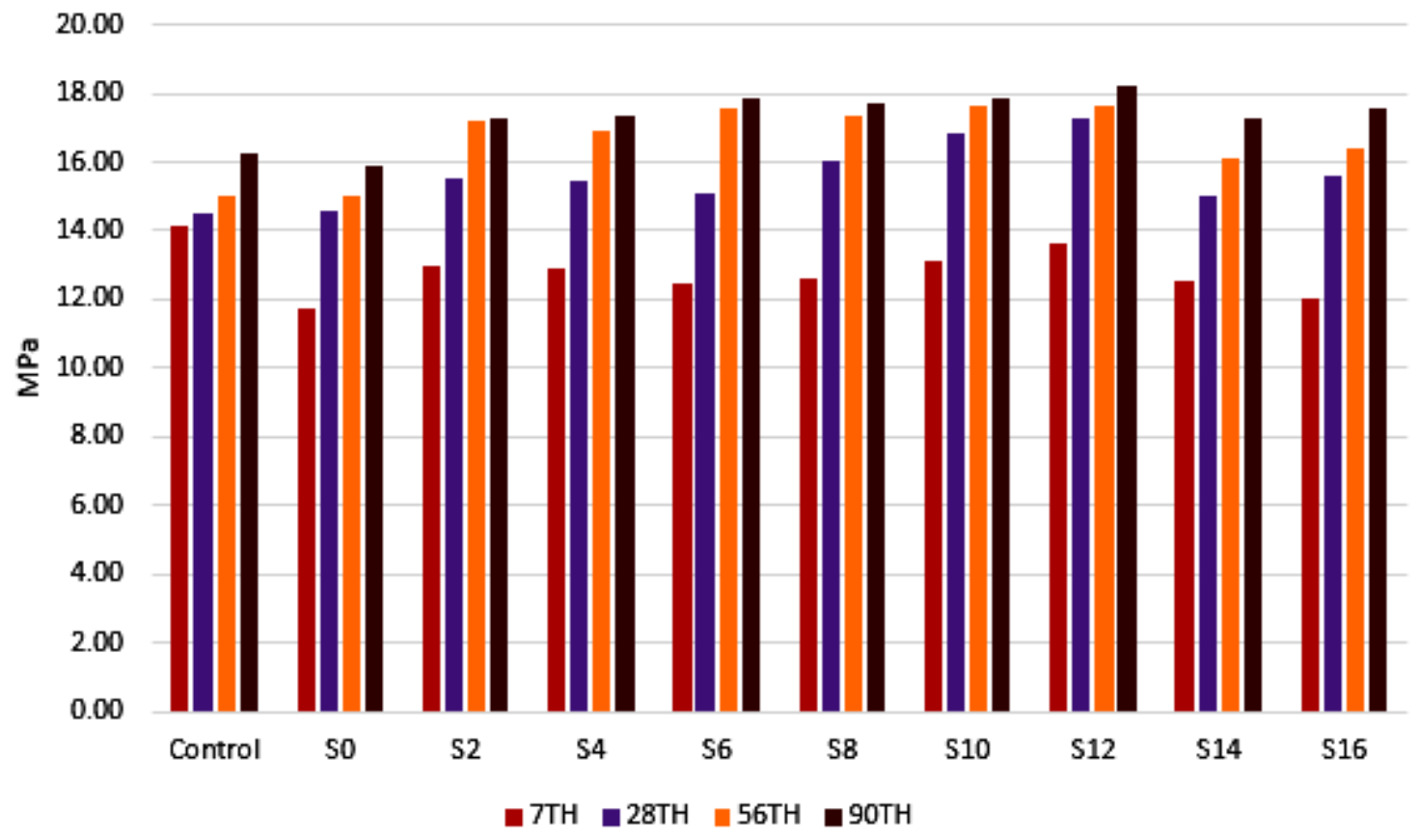

Figure 3. Flexural strength of mortars. 


\section{Compressive Strength}

The compressive strength of the mortars were evaluated and recorded as shown in Figure 4. In general, the trend of the compressive strength for every batch of mortars was similar to the flexural strength at the early age of 7 days. However, the difference was the compressive strength of control mix which was only 55.54 MPa. This exhibited a lower value than the other mortar mixes with DSF at 7 days. At the later ages, the compressive strength of most of the mortar mixes were similar with values of $77-78 \mathrm{MPa}$ at 28 days; $14.5 \%$ higher than the control. However, the compressive strength of the mortar with a higher DSF content namely S14 and S16 were slightly lower than S0 to S12 which were 8.2-10.2\% lower than the highest compressive strength achieved amongst the mixes. However, the compressive strength of the ternary blended mortar with GGBS and DSF were similar. S0 obtained slightly lower values but $13.40 \%$ higher than the control mix. In addition, S12 exhibited the highest compressive strength amongst the others which was $17.80 \%$ higher than the reference mix. The higher compressive strength achieved by those with DSF was due to the ultra-fine particles increasing the early strength gain of the system by acting as the nucleation site for cement hydration. At the same time, there was an increase in the reactivity of GGBS at the early stages by reacting $\mathrm{CaO}$ from the GGBS and producing secondary $\mathrm{C}$-A-S$\mathrm{H}$ and $\mathrm{C}-\mathrm{S}-\mathrm{H}$ gels. These contributed towards refining the microstructure of mortar that enhanced the bond between hydrated cement matrix and quarry dust. This proved that the S0 had a slightly lower compressive strength than those with DSF substitution at 7 days increasing at 28 days due to a slower hydration of GGBS. This was necessary to obtain a similar strength as those with both GGBS and DSF. For S14 and S16, the lower early compressive strength achieved may have been caused by a prolonged setting time due to the retarding effect caused by a high volume of DSF [4]. Hence, it can be concluded that the incorporation of DSF in the ternary blended system with different combination of GGBS and the DSF ratio improved the early aged compressive strength of mortar with quarry dust. The later aged compressive strength was comparable regardless of the substitution level of DSF.

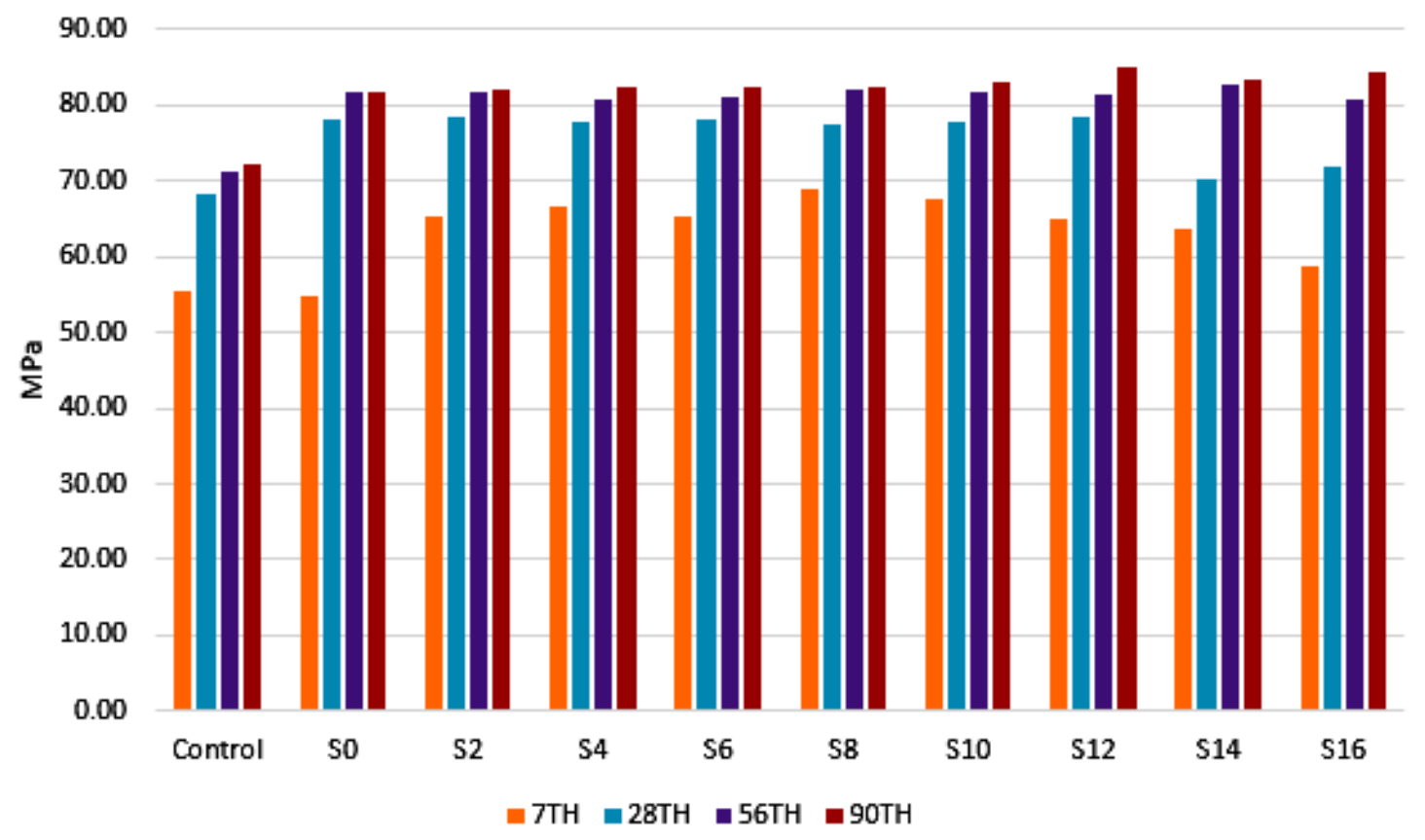

Figure 4. Compressive Strength of mortars.

\section{Drying Shrinkage}

The drying shrinkage results of mortar designs are depicted in Figure 5. The drying shrinkage of mortars was recorded according to the ages of 1, 3, 7, 28, 56, 90, 112 days. From test results obtained, it was been established that S0 with 50\% of GGBS substitution of OPC exhibited a lower degree of total shrinkage than the control OPC mix. A reduction in the drying shrinkage by approximately $74.1 \%$ at 28 days, $52.63 \%$ at 90 days and $29.2 \%$ at 112 days were observed for mix SO as compared to the control mix. The results were in close agreement with some prior study which stated that GGBS can reduce the degree of drying shrinkage in binary blended concrete. This is largely due to higher specific surface area of GGBS which resulted in a higher amount of chemically bound water, hence, reducing the rate of water loss from the concrete on drying exposure conditions $[2,27]$. However, when the DSF was used to substitute GGBS content in the ternary blended system of mortar, the drying shrinkage of mortar was generally reduced when as much as $8 \%$ DSF was used up to 90 days but exceeded the OPC mix at 112 days. The drying shrinkage strain value was increased significantly at an early age when the DSF content was below $8 \%$. The drying shrinkage of mortar containing DSF increased with the higher DSF substitution level. Hence, at low DSF content (2-4\%), the drying shrinkage of mortars increased significantly due to high reactivity of ultra-fine silica fume that increases the hydration rate of the mortar which exhibited a higher 
peak of drying shrinkage strain at 3 days but slowly reduced nearly to $0.0305 \mathrm{~mm}$ and $0.041 \mathrm{~mm}$ at 7 days for S2 and S4 respectively. For 6-8\% DSF content, a similar behaviour was observed. The peak shifted to 7 days. This can be explained by the significant drying shrinkage of mortar prolonged to 7 days rather than 3 days. The smaller capillary pore diameters formed in the mortars due to the pozzolanic reaction of GGBS and DSF. This enhanced the resistance to drying shrinkage at a 6-8\% DSF replacement level to GGBS in the ternary blended mortars. At a 10-12\% DSF content, the drying shrinkage of mortar at an early age was observed to be very low with only $0.005 \mathrm{~mm}$ and $0.003 \mathrm{~mm}$ at 3 days. The mixes continued to exhibit a low degree of drying shrinkage strain up to 7 days with the strain value around $0.004-0.005 \mathrm{~mm}$. This indicated that the drying shrinkage resistance of the mixes was higher at an early age which reduced the degree of drying shrinkage of the mortar. The drying shrinkage of these two mortars started to increase significantly at 28 days and reached their maximum value at 56 days which were $0.056 \mathrm{~mm}$ and $0.065 \mathrm{~mm}$ respectively. A similar trend of drying shrinkage strain was observed for S14 and S16. At 112 days, the dying shrinkage of S14 and S16 was higher than that of the OPC mix especially for S16 which was $36.9 \%$ higher. Hence, it can be concluded that GGBS reduces the drying shrinkage of mortar. Meanwhile, the inclusion of DSF in the ternary blended mortar which reduced the content of GGBS has weakened the influence of GGBS on drying shrinkage resistance. Also, the drying shrinkage of GGBS-DSF ternary blended cement mortar was lower when the DSF percentage was below $12 \%$ by total binder weight.

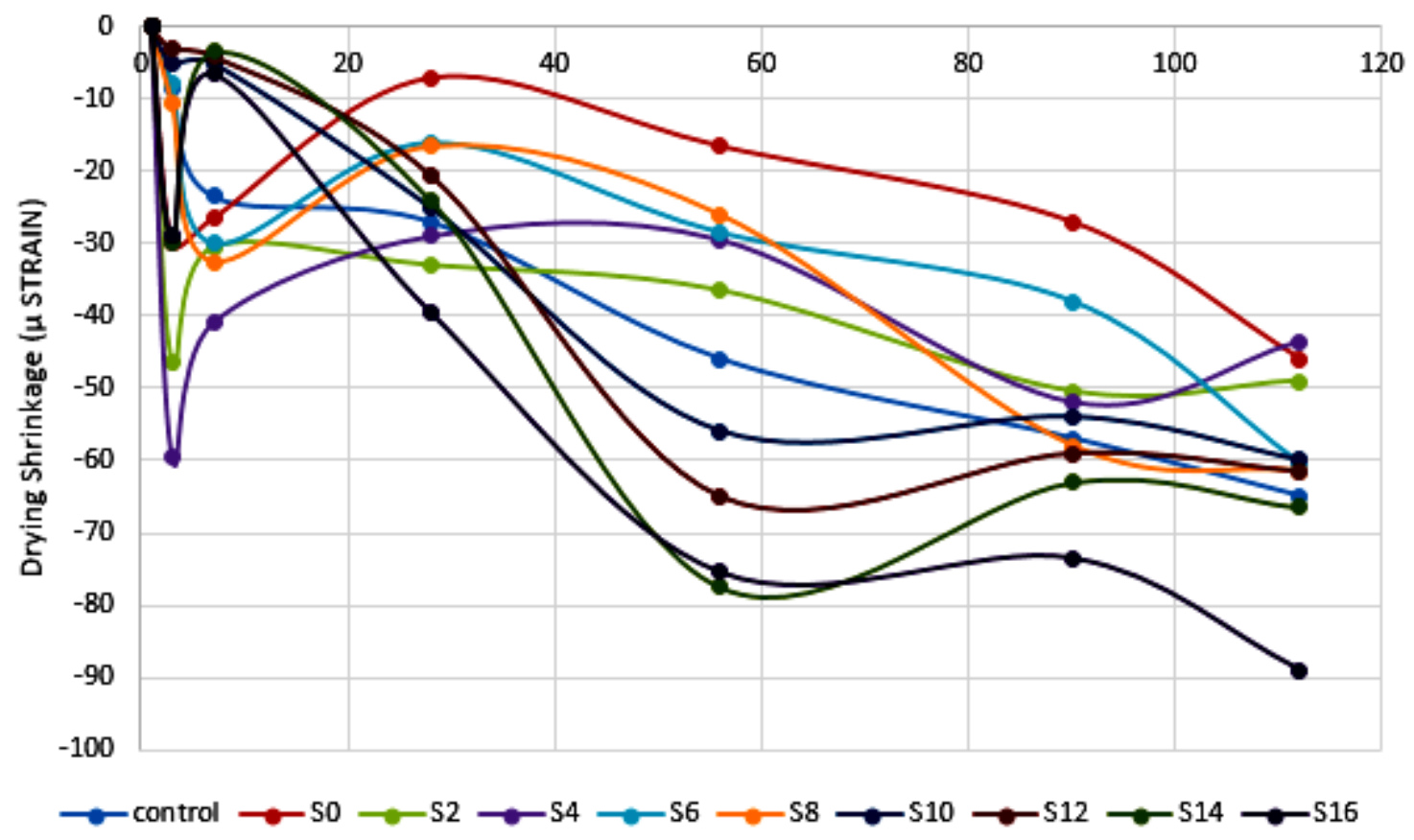

Figure 5. Drying shrinkage of mortars.

\section{Total Porosity}

The total porosity of mortar is an indication of the total pore volume present in a mortar matrix. The porosity of each mortar mixes are shown in Figure 6. The control mortar mix has shown a slightly lower porosity value at 7 days in comparison to GGBS-DSF mortars for S0 to S2. It was also observed that the porosity of the mortar was reduced gradually with the increasing DSF content from $4 \%$ up to $12 \%$. A significant increase in porosity of the mortar was observed at a high dosage of DSF between 14-16\%. This is largely due to insufficient Portlandite content for the pozzolanic reaction of GGBS and DSF and spiked increase of superplasticizer content at high levels of DSF at an early age [7, 26]. Increased porosity also resulted by an increase of viscosity of fresh mortar high in entrapped air that's difficult to escape which led to an increase in its total porosity of the hardened mortar [28]. Thus, it was reflected in the high total porosity values of $4.62 \%$ and $4.66 \%$ as recorded at 7 days for S14 and S16. On prolonged curing, the porosity of GGBS-DSF mortars was reduced significantly at 28 days onwards for those with high DSF content, from S10 to S16. At the age of 90 days, S10 and $\mathrm{S} 12$ attained the lowest porosity values which were $2.72 \%$ and $2.48 \%$ respectively or $37-42 \%$ lower than control mortars. This indicated that the microstructure could be improved effectively at a later age with a high percentage of DSF used in the mortar as compared to the neat OPC control mix. The control exhibited a relatively high porosity value between $4.3 \%$ and $4.5 \%$ at all testing ages. 


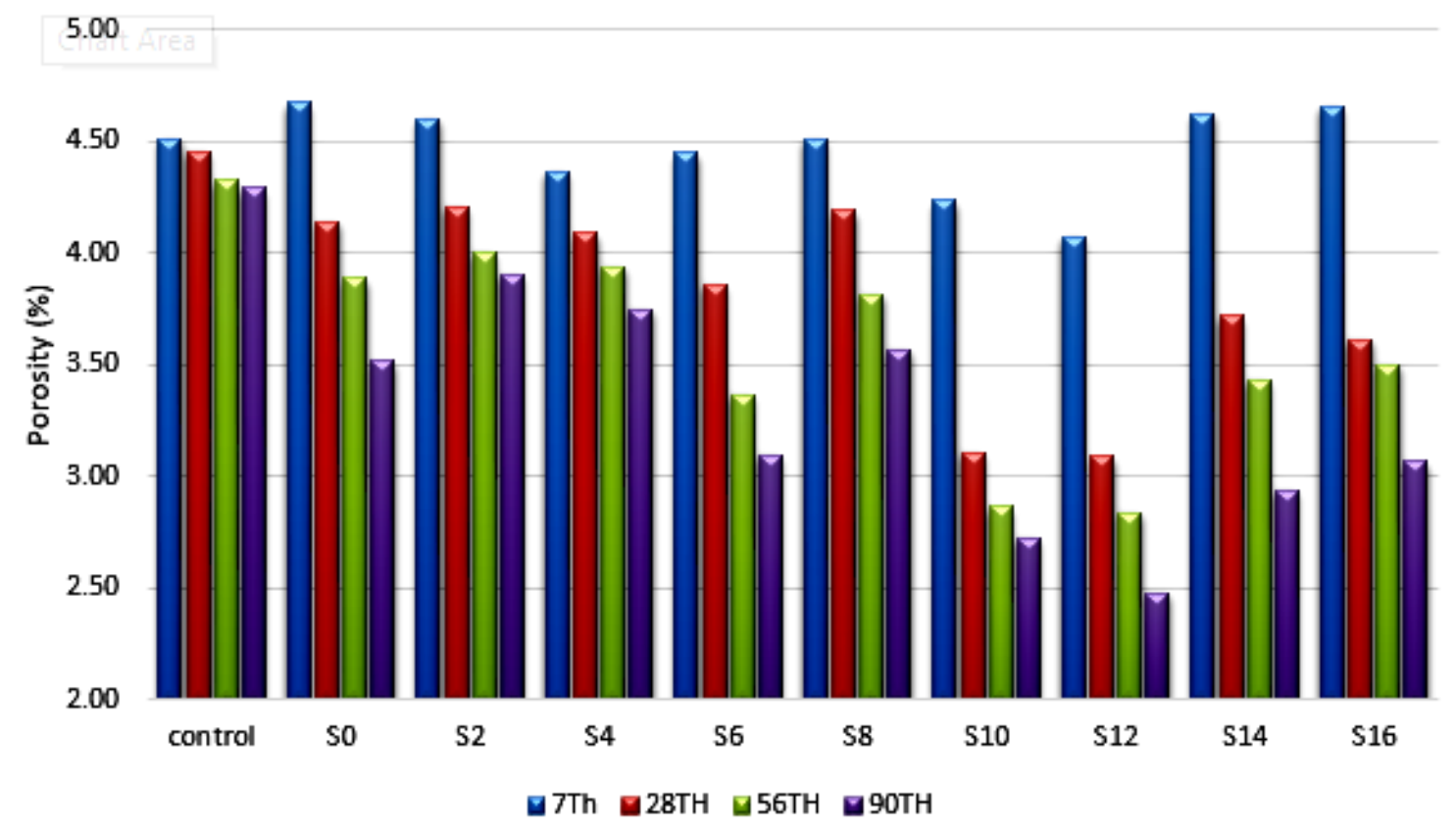

Figure 6. Porosity of mortars.

\section{CONCLUSIONS}

This study was based on the properties of ternary blended mortar incorporating GGBS and densified silica fume as supplementary cementitious materials. OPC was used as a binder replacement fully utilizing quarry dust as fine aggregates. Based on the results from various assessments the following conclusions of this study could be derived.

1. The use of GGBS as a partial replacement of cement improved the workability of the fresh mortar mixture and reduced the chemical admixture dosage. A given level of workability was achieved while DSF utilization gave an adverse effect due to its fineness.

2. The use of GGBS only in binary quarry dust mortar imposed a marginal improvement in flexural strength of the hardened mortar compared to neat OPC mortar. The presence of silica fume could effectively enhance the flexural strength of mortar in a ternary blended system with OPC and GGBS. This occurred at all substitution levels tested in this study.

3. The compressive strength of ternary blended mortar with DSF from $2 \%$ to $16 \%$ was higher than the control mix and S0 with 50\% GGBS substitution. Due to a higher pozzolanic activity of DSF rather than GGBS better pore refinement was achieved through the pore filling effects of DSF.

4. The drying shrinkage of S0 and ternary blended mortar with DSF content with less than $12 \%$ substitution level was lower than neat OPC mortar. This was especially true for S0 without any silica fume substitution. As the DSF content increased beyond $12 \%$, the drying shrinkage of mortar increased significantly with a higher total shrinkage than neat OPC mortar.

5. The total porosity of binary and ternary blended mortar containing GGBS and DSF was significantly lower than neat $\mathrm{OPC}$ mortar on an extended curing duration of 28 days and longer.

6. Therefore, all combined results obtained from various property measurements, it was concluded that the ternary blended high strength mortar incorporating GGBS and DSF with quarry dust as fine aggregates exhibited the optimum performances. These results could be seen at S12, with the binder combination ratio of $50 \%$ of OPC : $38 \%$ of GGBS : $12 \%$ of DSF.

7. A very high strength and low porosity cementitious composites could be produced by large volume substitutions of OPC with GGBS and DSF with granite quarry dust (a by-product from granite quarrying operation) as the sole aggregate phase.

\section{ACKNOWLEDGEMENTS}

The research described in this paper was financially supported by Macro Dimension Concrete Sdn. Bhd. and Universiti Sains Malaysia under the USM Industry Matching Research Grant.

\section{REFERENCES}

[1] Amudhavalli NK, Mathew J. Effect of silica fume on strength and Durability parameters of concrete. International Journal of Engineering Sciences \& Emerging Technologies. 2012;3(1):28-35.

[2] Jianyong L, Yan Y. A study on creep and drying shrinkage of high performance concrete. Cement and Concrete Research. 2001;31(8):1203-1206. 
[3] Liu J and Wang D. Influence of steel slag-silica fume composite mineral admixture on the properties of concrete. Powder Technology. 2017;320:230-238.

[4] Heikal M, El-Didamony H, Moustafa MA. Hydration and properties of blended cement systems incorporating industrial wastes. Ceramics - Silikaty. 2013;57(2):108-119.

[5] Inan Sezer G. Compressive strength and sulfate resistance of limestone and/or silica fume mortars. Construction and Building Materials. 2012;26(1):613-618.

[6] Flower DJM, Sanjayan JG. Greenhouse gas emissions due to concrete manufacture. Handbook of low carbon concrete. Elsevier Inc., 2016: 1-16.

[7] Oner A, Akyuz S. An experimental study on optimum usage of GGBS for the compressive strength of concrete. Cement and Concrete Composites. 2007;29(6):505-514.

[8] Khatib JM, Hibbert JJ. Selected engineering properties of concrete incorporating slag and metakaolin. Construction and Building Materials. 2005;19(6):460-472.

[9] López MM, Pineda Y. and Gutiérrez O. Evaluation of durability and mechanical properties of the cement mortar added with slag blast furnace. Procedia Material Science. 2015;9:367-376.

[10] El-Chabib H, Syed A. Properties of self-consolidating concrete made with high volumes of supplementary cementitious materials. Journal of Materials in Civil Engineering ( ) ASCE. 2013;25(11):1579-1586.

[11] Singh A, Patel RD, Raza K. A comparative study on compressive and flexural strength of concrete containing different admixtures as partial replacement of cement. Journal of Engineering Research and Applications.2014;4(9):118-123.

[12] Rao GA. Investigations on the performance of silica fume-incorporated cement pastes and mortars. Cement and Concrete Research. 2003;33(11):1765-1770.

[13] Alshamsi AM, Sabouni AR, and Bushlaibi AH. Influence of set-retarding superplasticizers and microsilica on setting times of pastes at various temperatures. Cement and Concrete Research. 1993;23(3):592-598.

[14] Hooton RD. Influence of silica fume replacement of cement on physical properties and resistance to sulfate attack, freezing and thawing, and alkali-silica reactivity. ACI Materials Journal. 1993;90(2):143-151.

[15] Thakur IC, Kisku N, Singh JP, and Kumar S. Properties of concrete incorporated with GGBS. International Journal of Reserch in Engineering and Technology. 2016;5(8):275-281.

[16] Ramezanianpour AA, Atarodi S. Durability of concretes containing ground granulated blast furnace GGBS against sulfate attack. In: 3rd International Conference on Sustainable Construction Materials an Technologies, Kyoto Research Park, Kyoto, Japan; 18-23 August, 2013.

[17] Khatri RP,Sirivivatnanon V, Gross W. Effect of different supplementary cementitious materials on mechanical properties of high performance concrete. Cement and Concrete Research. 1995; 25(1):209-220.

[18] American Society for Testing Materials, ASTM C109/C109M-16a, Standard Test Method for Compressive Strength of Hydraulic Cement Mortars. West Conshohocken, PA, 2016.

[19] American Society for Testing Materials, ASTM C305-14, Standard Practice for Mechanical Mixing of Hydraulic Cement Pastes and Mortars of Plastic Consistency. West Conshohocken, PA: ASTM International, 2014.

[20] American Society for Testing Materials, ASTM C230/C230M-14, Standard Specification for Flow Table for Use in Tests of Hydraulic Cement. West Conshohocken, PA: ASTM International, 2014.

[21] American Society for Testing Materials, ASTM C192/C192M-18, Standard Practice for Making and Curing Concrete Test Specimens in the Laboratory. West Conshohocken, PA: ASTM International, 2018.

[22] American Society for Testing Materials, ASTM C348-18, Standard Test Method for Flexural Strength of Hydraulic-Cement Mortars. West Conshohocken, PA: ASTM International, 2018.

[23] American Society of Testing Materials, ASTM C349-18, Standard Test Method for Compressive Strength of Hydraulic-Cement Mortars (Using Portions of Prisms Broken in Flexure). West Conshohocken, PA: ASTM International, 2018.

[24] American Society for Testing Materials, ASTM C596-18, Standard Test Method for Drying Shrinkage of Mortar Containing Hydraulic Cement. West Conshohocken, PA: ASTM International, 2018.

[25] Siddique R, Khan M. Silica fume. Supplementary cementing materials. Springer, 2011, p 67-119.

[26] Zhang W, Hama Y, Na SH. Drying shrinkage and microstructure characteristics of mortar incorporating ground granulated blast furnace slag and shrinkage reducing admixture. Construction and Building Materials. 2015;93:267-277.

[27] Kadri EH, Duval R. Hydration heat kinetics of concrete with silica fume. Construction and Building Materials. 2009;23(11):3388-3392.

[28] Yu R, Spiesz P, Brouwers HJH. Effect of nano-silica on the hydration and microstructure development of ultra-high performance concrete (UHPC) with a low binder amount. Construction and Building Materials. 2014;65:140-150. 